\title{
Launch Vehicle Demonstrator Using Shuttle Assets
}

\author{
Abstract \\ Grady E. Threet, Jr. \\ NASA, George C. Marshall Space Flight Center, AL, 35812, United States \\ Dennis M. Creech \\ Jacobs Engineering - Jacobs, ESTS Group, Huntsville, AL, 35806, United States \\ Alan D. Philips \\ NASA, George C. Marshall Space Flight Center, AL, 35812, United States \\ Eric D. Waters \\ Dynamic Concepts Inc - Jacobs, ESTS Group, Huntsville, AL, 35806, United States
}

The Marshall Space Flight Center Advanced Concepts Office (ACO) has the leading role for NASA's preliminary conceptual launch vehicle design and performance analysis. Over the past several years the ACO Earth-to-Orbit Team has evaluated thousands of launch vehicle concept variations for a multitude of studies including agency-wide efforts such as the Exploration Systems Architecture Study (ESAS), Constellation, Heavy Lift Launch Vehicle (HLLV), Heavy Lift Propulsion Technology (HLPT), Human Exploration Framework Team (HEFT), and Space Launch System (SLS).

NASA plans to continue human space exploration and space station utilization. Launch vehicles used for heavy lift cargo and crew will be needed. One of the current leading concepts for future heavy lift capability is an inline one and a half stage concept using solid rocket boosters (SRB) and based on current Shuttle technology and elements. Potentially, the quickest and most cost-effective path towards an operational vehicle of this configuration is to make use of a demonstrator vehicle fabricated from existing shuttle assets and relying upon the existing STS launch infrastructure. Such a demonstrator would yield valuable proof-of-concept data and would provide a working test platform allowing for validated systems integration. Using shuttle hardware such as existing RS-25D engines and partial MPS, propellant tanks derived from the External Tank (ET) design and tooling, and four-segment SRB's could reduce the associated upfront development costs and schedule when compared to a concept that would rely on new propulsion technology and engine designs.

There are potentially several other additional benefits to this demonstrator concept. Since a concept of this type would be based on man-rated flight proven hardware components, this demonstrator has the potential to evolve into the first iteration of heavy lift crew or cargo and serve as a baseline for block upgrades. This vehicle could also serve as a demonstration and test platform for the Orion Program. Critical spacecraft systems, re-entry and recovery systems, and launch abort systems of Orion could also be demonstrated in early test flights of the launch vehicle demo. Furthermore, an early demonstrator of this type would provide a stop-gap for retaining critical human capital and infrastructure while affording the current emerging generation of young engineers opportunity to work with and capture lessons learned from existing STS program offices and personnel, who were integral in the design and development of the Space Shuttle before these resources are no longer available.

The objective of this study is to define candidate launch vehicle demonstration concepts that are based on Space Shuttle assets and determine their performance capabilities and how these demonstration vehicles could evolve to a heavy lift capability to low earth orbit. 